\title{
DESIGN DO BRINCAR NO ESPAÇO URBANO: FORMAS DE APROPRIAÇÃO NO “MINHOCÃO" PELAS CRIANÇAS
}

\author{
Graziela Nivoloni \\ Universidade de São Paulo - FAUUSP \\ nivoloni@usp.br \\ Denise Dantas \\ Universidade de São Paulo - FAUUSP \\ dedantas@usp.br \\ Clice de Toledo Sanjar Mazzilli \\ Universidade de São Paulo - FAUUSP \\ clice@usp.br
}

Resumo: Propõe-se, com este artigo, analisar como as crianças, ao brincarem livremente em espaços não destinados ao lazer, relacionam-se entre si e interagem com o espaço urbano. Considera-se fundamental a tentativa de compreensão da maneira como algumas crianças ainda se relacionam com o meio urbano, considerando-se que, gradativamente, elas o usam menos e muitas delas já não se identificam com sua cidade, tampouco reconhecem-na como sua. Stakeholding Map e Abstraction Ladder, ferramentas metodológicas de pesquisa centrada no usuário, foram exploradas durante o estudo em que foram observadas crianças no viaduto Elevado Costa e Silva, conhecido como "Minhocão", na região central da cidade de São Paulo. O protocolo de coleta de dados visuais foi realizado por meio da observação não participante do pesquisador $\mathrm{e}$ análise, em intervalos de tempo predefinidos, de alguns aspectos gerais como presença de pais e adultos responsáveis, participação ou não destes no brincar, a faixa etária das crianças e a classificação de situações recorrentes - que emergiram conforme os dados foram sendo coletados e avaliados. Configuraram-se, assim, quatro formas de apropriação do espaço urbano em questão. São elas: caminhar sobre a mureta; andar sobre a risca; gerar percursos; desafio da escalada e do equilíbrio. Instaurar um novo olhar para o brincar, a fim de estimulá-lo ou explorá-lo, objetivando que aconteça da mais rica forma, representa grande desafio para a complexa e multidisciplinar atividade do designer.

Palavras-chave: design, livre brincar, criança, espaço urbano, apropriação urbana.

Abstract: It is proposed to this article, examine how children, to freely play in spaces not intended for leisure, they relate to each other and interact with the urban space. It is considered essential to understand the way some 
children still relate to the urban environment, considering that, gradually, they use it less and many of them no longer identify with their city, nor recognize it as his own. Stakeholding map and abstraction ladder, methodological tools of research centered on the user, were explored during the study in which children were observed on the overpass High Costa e Silva, known as "Minhocão" in the central region of São Paulo. The visual data collection protocol was performed by non-participant observation and analysis, at predefined time intervals, some general aspects such as the presence of parents and responsible adults, participation or not of these in play, the age of children and classification of recurrent situations - that emerged as the data were being collected and evaluated. Configured is thus four ways of appropriation of urban space in question. They are: walking on the short wall; walk on the letter; generate paths; challenge of climbing and balancing. Establish a new look to play in order to stimulate it or exploit it, aiming to happen in the richest form, it represents a challenge for the complex and multidisciplinary activity designer.

Key-words: design, free playing, children, urban space, urban appropriation.

\section{INTRODUÇÃO}

If [the cities] are not meant for children, they are not meant for citizens either. If they are not meant for citizens - ourselves - they are not cities. (EYCK, 1962, apud MARTINHO, 2014, p.4)

Propostas urbanísticas de grande escala, com intervenções de profunda transformação de viés universalizante, pragmático e abstracionista, foram frequentes no Movimento Moderno. Uma pequena parte delas, consideradas exceções, observando o homem de maneira local com suas idiossincrasias, em distintas partes do mundo como Inglaterra, Holanda e Brasil, trouxeram, à tona, a importância da presença infantil e, consequentemente o brincar na cidade - seja em espaços verdes e parques equipados, seja nas ruas e calçadas - como um possível elemento catalisador para aproximar pessoas, aumentar a percepção de segurança, como também suscitar sentimento de pertencimento, identidade e cidadania.

Se o brincar não for uma prioridade, continuaremos a ver, em nossas crianças, a diminuição da criatividade e da imaginação, e da mesma forma, reduzir-se-ão habilidades vitais como curiosidade, convívio social, resiliência e a capacidade de avaliar riscos. (GOLINKOFF, 2006)

Compreender o brincar de forma aprofundada e seu papel no desenvolvimento cognitivo, físico e, principalmente, psicossocial infantil é basilar. Acredita-se que, brincando, a criança interfira e aja no mundo real, nos espaços e nos objetos e, por meio desta ação, ela o recrie e o reinvente, atribuindo-lhe valor próprio, subjetivo. Portanto, permitir à criança que o faça, que o construa, é permitir que "construa" a si mesma, que se reconheça, e que, a partir disso, seja livre, espontânea, autônoma e 
criativa. Segundo Winnicott, trata-se da primeira experiência cultural do homem (WINNICOTT, 1975), conforme citação:

Sentir-se real é mais que existir; é descobrir um modo de existir em si mesmo, relacionar-se com os objetos como a si mesmo e ter um eu para o qual retirar-se, para relaxamento. (WINNICOTT, 1975, p.185).

Desta forma, compreende-se que o brincar é uma linguagem - a primeira -, e é também "meio para a produção de cultura" (NASCIMENTO, 2009, p.36). Por isso, sua pertinência para o convívio em sociedade. $E$, ao designer que pretende projetar para o brincar, cabe potencializá-lo, provocando-o, liberando-o e suscitando a criança a fazêlo, sem restringi-la, coibi-la ou cerceá-la. Dessarte, a relevância de observá-la, durante o brincar espontâneo, em locais considerados impróprios para tal.

É no brincar, e somente no brincar, que o indivíduo, criança ou adulto pode ser criativo e utilizar sua personalidade integral: e é somente sendo criativo que o indivíduo descobre o eu (self). (WINNICOTT, 1975, p. 89)

Alguns aspectos socioeconômicos e comportamentais trazem à tona a importância do brincar autônomo, livre na cidade, como oportunidade de convívio social pois, segundo o Instituto Brasileiro de Geografia e Estatística (IBGE), está se formando uma geração de unigênitos, os chamados filhos únicos. Este dado oculta uma série de questões recorrentes, mas não exclusivas, neste arranjo familiar que é a dificuldade, por parte destas crianças, em compartilhar, conviver, repartir, aguardar (a sua vez), ter autonomia etc.

Outro aspecto considerável é que cidades grandes e capitais, como São Paulo em que um terço da sua população reside em condomínios, sofrem uma transformação física através da proliferação destes conglomerados, cercados e murados, vigiados e monitorados, nos quais se organizam famílias e pessoas de igual poder aquisitivo.

A este fenômeno, acrescentamos a divisão das cidades em ilhas e bolhas, com circuitos invisíveis aos olhos, mas repletos de restrições e regras, frequentados por pessoas de renda financeira semelhante, em alguns casos, até fisicamente parecidas, que fazem uso dos mesmos utensílios, vestuários, gadgets e grifes, como restaurantes, escolas, shopping centers, clubes, academias de ginásticas etc.

Também podem ser citados aqueles, considerados privilegiados, que frequentam boas e renomadas escolas, e recebem, via de regra, uma educação totalmente direcionada à memorização das disciplinas, às respostas prontas, aos métodos educacionais generalizantes, à clássica subdivisão do conhecimento etc. Escolas cujo sucesso é avaliado pelo resultado em provas como Exame Nacional do Ensino Médio (Enem) e outros vestibulares. Nessas instituições de ensino, o brincar é tido como perda de tempo, sem outra função que não seja a distração ou o gasto de energia.

E, por fim, no interior das casas, há a propagação de brinquedos eletrônicos e solitários, em que, a cada toque ou ação, há uma resposta pré-programada sob a forma de luz, cor, música, movimento etc. São artefatos que desconsideram a capacidade criadora da criança e não estimulam a criatividade, liberdade de apropriação e uso, multiplicidade de interação entre seus usuários etc. 
A preocupação, no que se refere à qualidade de vida e formação de cidadãos melhores, torna-se ainda maior porque, foram apontados nesta seção, até o presente momento, apenas aqueles que integram a pequena parcela da população, composta por aproximadamente dez por cento, e que consomem por volta de noventa por cento de tudo o que é projetado ou desenvolvido por profissionais do design no mundo todo, conforme a exposição intitulada Design for the other 90\%, idealizada em 2007 pelo Instituto de Educação e Pesquisa Smithsonian. E aos outros noventa por cento da população, o que é oferecido nesse sentido?

Com esse panorama sociocultural e econômico, gerar espaços, produtos, soluções e alternativas para que crianças de todas as classes sociais, culturais e regiões possam se encontrar e, nelas, "incentivar manifestações espontâneas presentes no local" (BARDI, 1996), é possibilidade e responsabilidade para o design e para a arquitetura. E é fundamental para o resgate da cidade como palco de troca, de confronto, de intercâmbio, para a preservação da identidade e construção da coletividade e cidadania.

[sobre o brincar] é busca pela conquista de autonomia, no sentido da formação de um jeito próprio de perceber o mundo, interpretálo, apropriar-se dele e agir, produzindo outros mundos possíveis e resistindo a meios determinantes e pouco criativos de viver. (NASCIMENTO, 2009, p.36)

\section{DESENVOLVIMENTO}

Cicatriz urbana, icônico viaduto cercado por polêmica, inaugurado em pleno regime militar em 1971, exemplar do planejamento urbano que prioriza automóveis e destitui o espaço urbano de seus cidadãos, o Elevado Costa e Silva (figura 1) fica no bairro de Santa Cecília, região central da cidade de São Paulo, possui aproximadamente 2.730 metros, largura média de vinte metros, 5,50 metros de altura e, em alguns pontos, distancia-se apenas cinco metros de alguns edifícios existentes.

Urbano, cinza, seco, árido, ensolarado, rude, congestionado, residual, o viaduto mais emblemático da cidade transforma-se radicalmente, aos sábados, domingos, feriados e diariamente entre $21 \mathrm{~h} 30$ e $6 \mathrm{~h} 00$, quando passa a ser utilizado como área de lazer ao ar livre, como um local para o esporte, um palco para eventos artísticos, gastronômicos e de moda. Torna-se plural, universal, diverso, espaço das pessoas e das crianças. Esse é o espaço escolhido para o desenvolvimento da coleta de dados sobre o brincar infantil. 


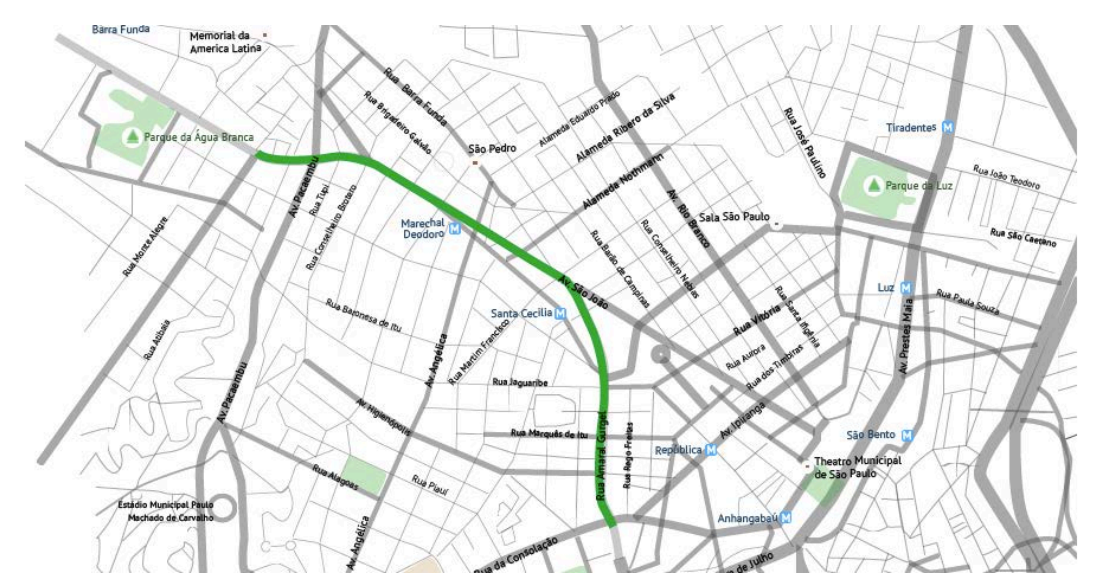

Figura 1 - Mapa do Elevado Costa e Silva, o "Minhocão".

Fonte: <http://minhocao.org/mapa-2/>. Acesso em: 16 out. 2015.

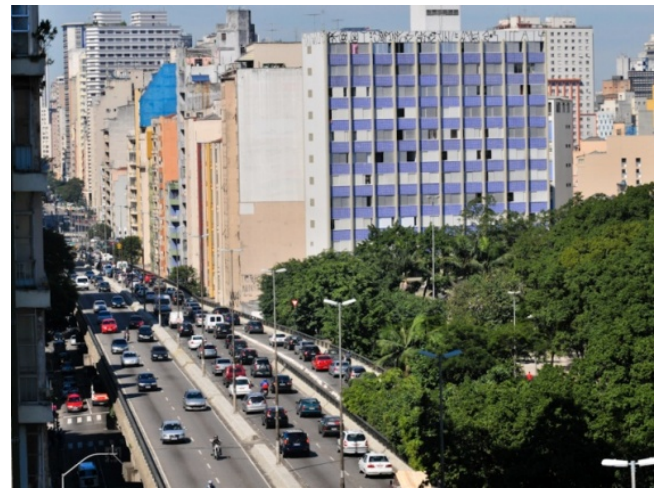

Figura 2 - Foto de carros circulando no Elevado Costa e Silva, o "Minhocão". Fonte: $<$ http://noticias.r7.com/saopaulo/fotos/demolicao-do-minhocao-divideopinioes-20100507-21.html>. Acesso em: 10 jun. 2016.

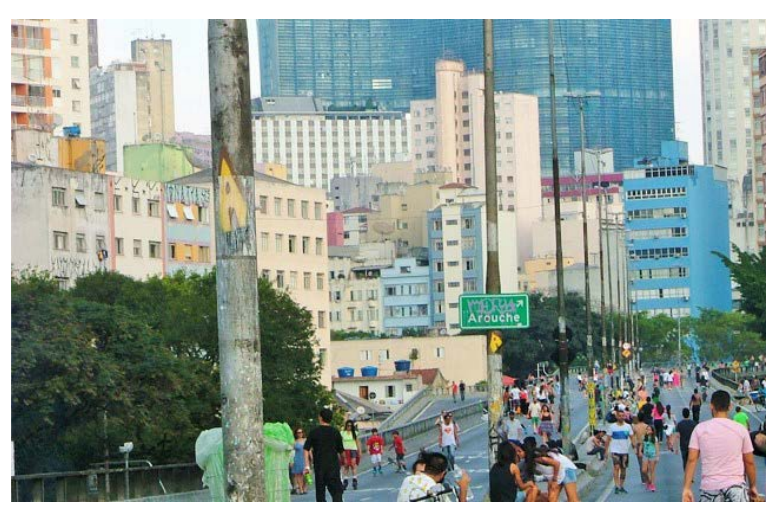

Figura 3 - Foto de pessoas usando o Elevado Costa e Silva, o “Minhocão".Fonte: $<$ https://amesaopaulo.wordpress.com/2015/08/1 2/elevado-costa-e-silva-minhocao/>. Acesso em: 10 jun. 2016.

\subsection{0 estudo}

Enfocando, como questão central da pesquisa, a importância do resgate do brincar infantil livre nas grandes cidades brasileiras, utilizou-se a ferramenta conhecida por abstraction ladder (figura 2), desenvolvida pelo linguista americano S.I. Hayakawa (1990). Esta ferramenta exercita os processos de abstração da mente humana, de modo a permitir um trânsito entre as questões mais abstratas e as mais concretas. $A$ adaptação desta ferramenta ao universo do design permite um maior aprofundamento nos processos, fortalecendo a relação entre os conceitos e as soluções. Por meio dela, é possível estabelecer um raciocínio que se torna mais complexo, universal e conceitual - "subindo seus degraus"- ou abordar o tema de forma mais prática e estratégica - "descendo seus degraus.

Neste raciocínio mais abstrato e abrangente, interroga-se porque as crianças precisam brincar no meio urbano. A resposta é a importância de se estimular o convívio, a interação e a apropriação do espaço público, à qual se discute porque ser necessário as crianças se apropriarem da cidade. Essa, por sua vez, é replicada pela 
possibilidade de suscitar, assim, sentimento de identidade e pertencimento, que seria, portanto, uma possibilidade de melhorar a vida em sociedade / comunidade.

No caminho inverso, "descendo" a partir da pergunta central, podemos estabelecer questões norteadoras e práticas em relação às medidas a serem tomadas e estratégias a serem traçadas durante a investigação. A partir dela, portanto, como perceber aspectos relevantes em relação ao brincar na cidade, à qual seria direcionada por meio da observação de como as crianças, ao brincarem livremente, lidam com as restrições e possibilidades que o espaço público não destinado ao lazer lhes oferece. A essa questão, seguiria como seria possível potencializar o brincar na cidade e, para tanto, seria fundamental tentar compreender se há parâmetros, similitudes ou comportamentos equivalentes na relação com o espaço urbano por meio da observação não participativa.

O homem liberado, criança, se movimenta, dança, vivencia sensações e mitos. Brinca, convive, contracena com seus companheiros na praça que é parque e teatro. Conversa com figuras fantásticas [...] que emergem da memória (ALMEIDA, 1997, p. 49).

Além dessa ferramenta, utilizou-se outra forma de aprofundar a investigação e apreendê-la de maneira mais completa, o stakeholder map. Trata-se, sem grandes pormenores, de mapear e localizar todos os agentes e pessoas envolvidas no processo, direta ou indiretamente, e, em que escala, podem influenciar o usuário central: as crianças (figura 3). Esta ferramenta, oriunda da área da Administração, permite que se tenha uma visão mais abrangente das relações entre todos os agentes. $\mathrm{O}$ círculo menor denominado escola, interno à criança, representa o imaginário e repertório que faz parte do cotidiano e universo infantil, e por isso, foi considerado relevante para o fenômeno a ser observado.

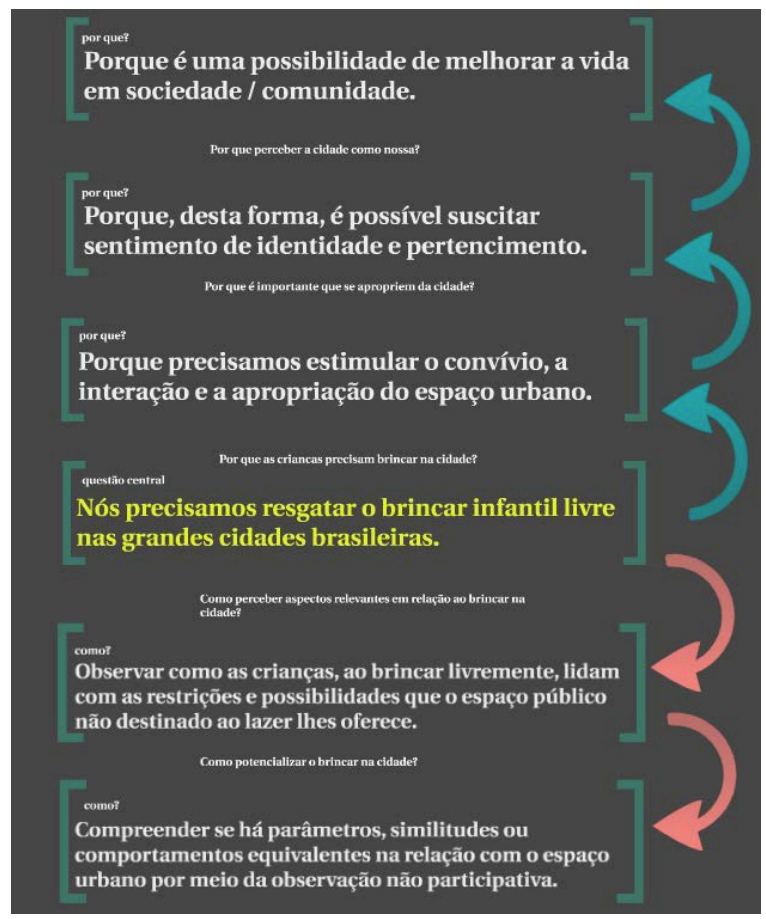

Figura 4 - Diagrama abstraction ladder. Fonte: elaborado por Graziela Nivoloni (2015), com base na pesquisa realizada.

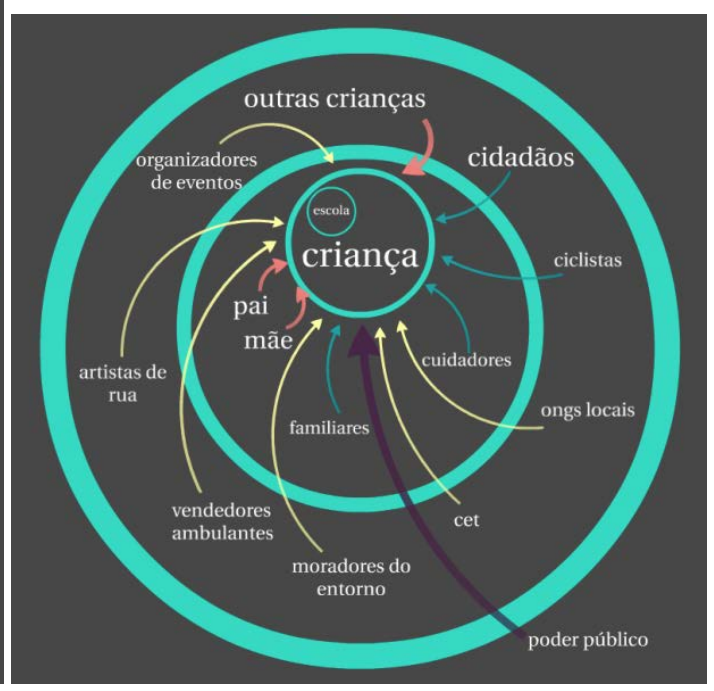

Figura 5 - Diagrama stakeholder map. Fonte: elaborado por Graziela Nivoloni (2015), com base na pesquisa realizada. 


\subsection{0 método}

Observar mais de perto, com o mínimo de expectativa possível, as cenas e os acontecimentos mais comuns, tentar entender o que significam e ver se surgem explicações entre eles. (JACOBS, 2001, p.12)

O método adotado para a coleta de dados foi a observação não participante. 0 protocolo adotado, fundamentado em dados visuais, de cunho exploratório e não confirmatório segundo Banks (2010), consistiu na observação focal de uma criança ou o grupo que a continha, escolhido de forma aleatória, por um intervalo de tempo predeterminado de quinze minutos no espaço público selecionado, o qual não fora destinado para o brincar infantil e que, diversamente, mostra-se pouco amigável ao uso para tanto.

Foram observadas dezesseis crianças em dez situações distintas nos dias dois de novembro, um domingo, e vinte de novembro, uma sexta-feira, feriado municipal da Consciência Negra na cidade de São Paulo, no ano de 2015, no período da manhã, por aproximadamente, duas horas.

Foram excluídas do estudo as crianças que o utilizavam apenas para andar de bicicleta, skate, patins e outros itens semelhantes porque acredita-se que não proporcionariam ou suscitariam, entre as elas, devido à velocidade e dinâmica de uso, o convívio, a interação, ou mesmo novas possibilidades de utilização e apropriação do espaço público para brincar livremente.

Para enriquecer a observação não participante, foram analisados os grupos que continham crianças, a idade delas, a dinâmica estabelecida, a participação ou não dos adultos nessa dinâmica, se foi feito o uso de algum elemento do espaço urbano em questão e se ocorreu a utilização de algum objeto ou brinquedo.

Em relação à faixa etária, foram divididas em dois grupos: crianças com idade entre um e cinco anos e crianças entre seis e catorze anos. O primeiro deles é composto por crianças pré-escolares ${ }^{1}$, por serem aquelas cuja aprendizagem dá-se, essencialmente, pela educação não-formal, ou seja, por meio de experiências, vivências e do brincar. São aquelas que, além de explorarem o espaço de maneira própria, estão passando por acentuado desenvolvimento cognitivo, físico, emocional e de linguagem. No segundo grupo, conhecido pela idade escolar, o conhecimento é adquirido, fundamentalmente, pela educação formal das escolas. Essas crianças estão sendo ou já foram alfabetizadas e a ênfase, em relação ao seu desenvolvimento, é dada à linguagem.

\subsection{Resultados obtidos}

Nas situações observadas, apreenderam-se, essencialmente, quatro dinâmicas de interação, uso ou apropriação do espaço urbano: caminhar sobre a mureta; andar sobre a risca; gerar percursos e desafio da escalada e do equilíbrio. Percebe-se que algumas delas aconteceram concomitantemente e outras se alternaram no mesmo grupo. Por isso, conclui-se que em todas as crianças

\footnotetext{
${ }^{1}$ Informação e caracterização fornecidas por Caitlin O'Connell e Helen Lawrence no curso intitulado Early Childhood Education fornecido pelo site learn 2 study. Disponível em:

<https://www.open2study.com/courses/early-childhood-education>, acesso em: 15 jan. 2016.
} 
observadas, o desejo de interagir com o espaço, por mais restritivo que ele fosse, foi extremamente forte.

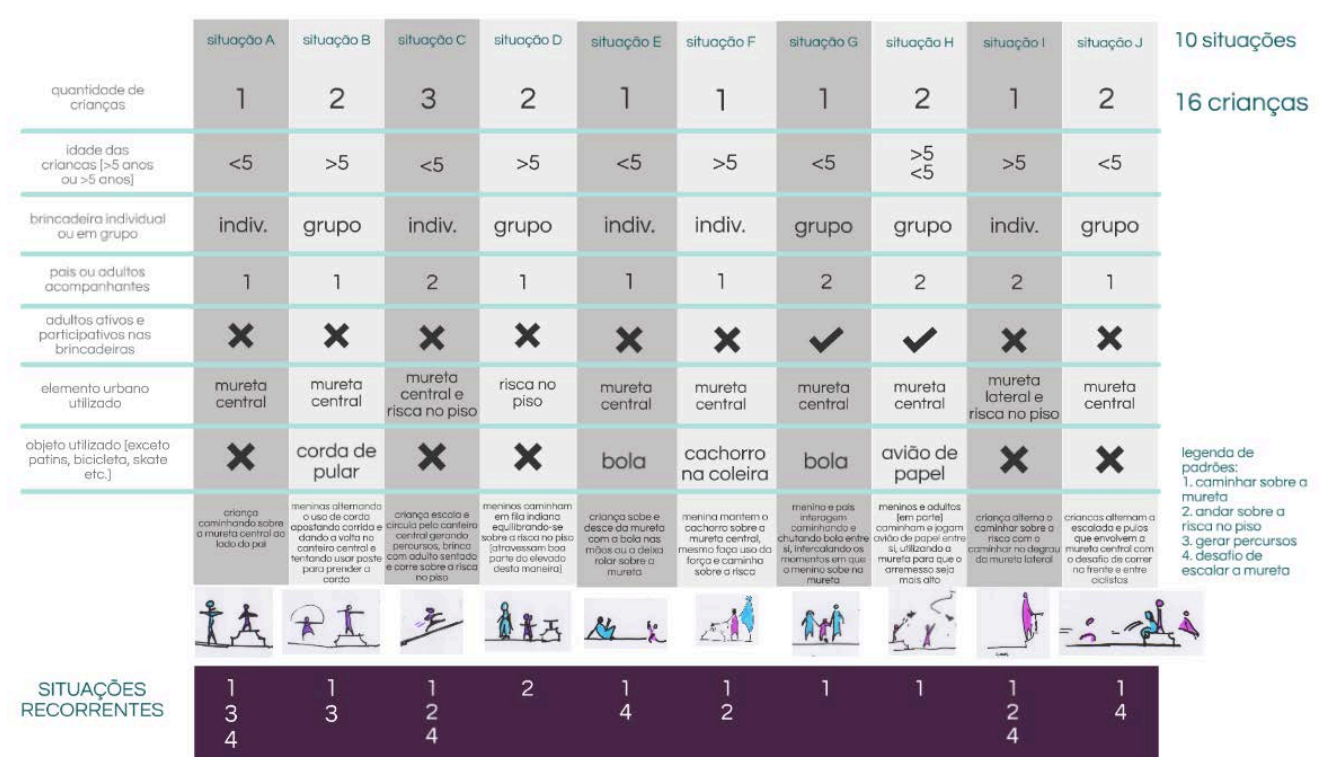

Figura 6 - Tabela esquemática das dinâmicas recorrentes nas situações observadas. Fonte: Elaborado por Graziela Nivoloni (2015), com base na pesquisa realizada.

\subsubsection{Caminhar sobre a mureta (figura 7)}

Além das muretas laterais em concreto com um corte curvilíneo, do tipo "peito de pombo", há uma central - mais explorada e mais larga -, separando as duas vias de sentidos opostos, com aproximadamente $45 \mathrm{~cm}$ de altura e $60 \mathrm{~cm}$ de largura, amplamente utilizada pelas crianças. Esse elemento urbano que, para uma grande parte dos adultos é apenas um local para se sentar-, permite, às crianças, muitas possibilidades de apropriação. Entre elas, as mais comuns visualizadas foram subir, descer, pular, escalar, "crescer" e "olhar do alto". Em alguns casos, observou-se que elas percebiam o espaço diferentemente quando estavam no asfalto do Elevado e quando subiam no canteiro pela forma como interagiam com os adultos, com as outras crianças e como observavam, sob este ponto de vista mais alto, o próprio espaço onde estavam brincando.

\subsubsection{Andar sobre a risca (figura 8)}

Aproveitando-se de marcas pintadas no asfalto para direcionamento e organização do trânsito, algumas crianças divertem-se caminhando sobre ela, evitando-a ou movimentando-se em ziguezague. Não foi percebida a utilização destas riscas para demarcar campos e criar jogos ou outra dinâmica semelhante. Inclusive, alguns adultos interagem, de alguma forma e por algum tempo, com a pintura no piso. A forma mais comum foi o caminhar sobre a risca, abrindo os braços individualmente ou em grupo, quando formava-se uma fila indiana de crianças. 

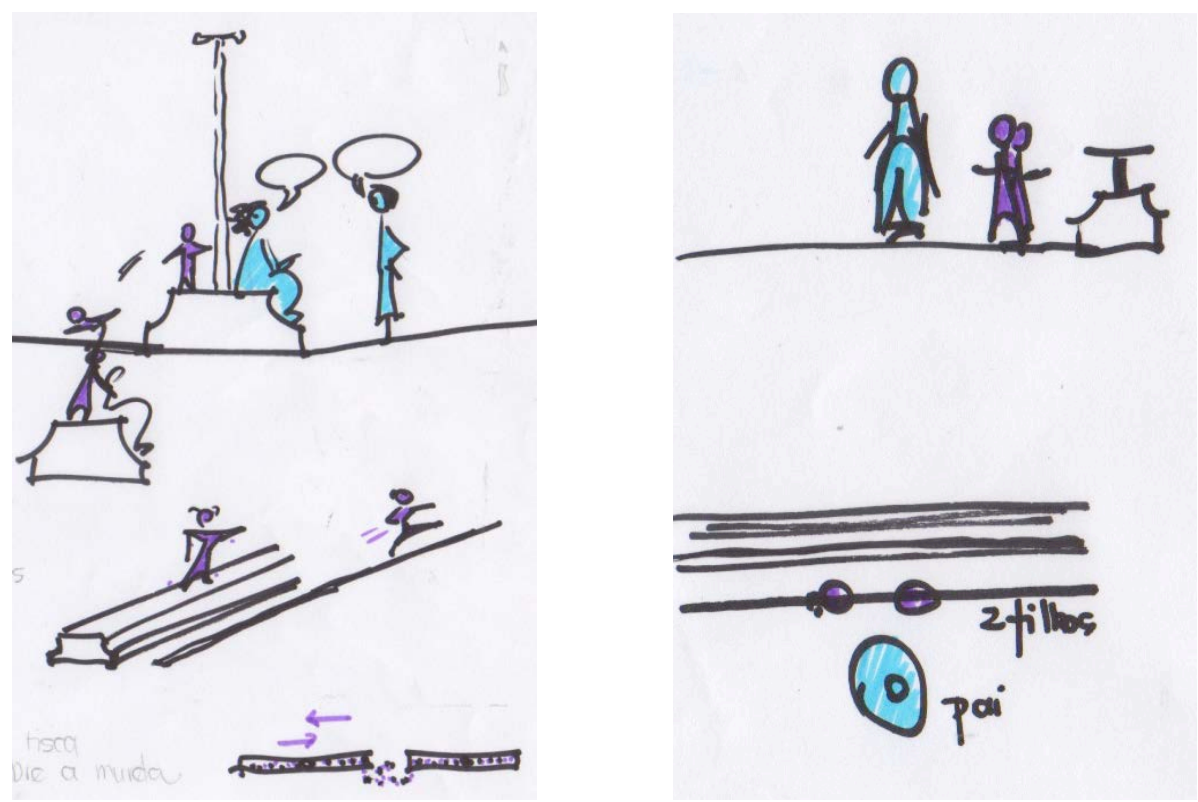

Figura 7 - Croqui representa a situação 1 caminhar sobre a mureta: criança corre, caminha, "desfila"e interage com a mãe.

Figura 8 - Croqui representa a situação 2 caminhar sobre a risca: crianças em fila indiana acompanhadas pelo pai.

Fonte: elaborado por Graziela Nivoloni (2015), com base na pesquisa realizada.

\subsubsection{Gerar percursos (figura 9)}

Inventando formas de se deslocar no espaço, contornando os canteiros centrais, utilizando a pintura no piso, circundando postes de iluminação ou interagindo com pessoas que frequentam o local, as crianças criam percursos inusitados e costumavam repetir suas sequências e aplicá-las novamente com certa liberdade, seus padrões criados.

Contornar o canteiro central e subir nele pela lateral, percorrê-lo integralmente e descer novamente pela lateral foi uma das formas observadas com certa frequência. Outra forma de fazê-lo, em grupo, envolvia a rapidez e a habilidade para apostar corrida da forma convencional ou, como se observou em uma das situações, uma criança pulava corda enquanto a outra corria para saber quem contornaria antes o canteiro onde a mãe ou responsável de uma delas estava acomodada.

\subsubsection{Desafio da escalada e do equilíbrio (figura 10)}

Na maioria dos casos, a escalada era realizada na mureta central, ao subi-la, pelas crianças menores de cinco anos. Já o desafio do equilíbrio ocorreu em duas situações: quando caminhavam ou corriam sobre o canteiro central ou quando o faziam sobre a risca pintada no piso. Em todos os casos observados, as crianças abriam os braços dando a impressão de que, neste momento, tinham plena consciência do seu corpo em relação ao espaço. 

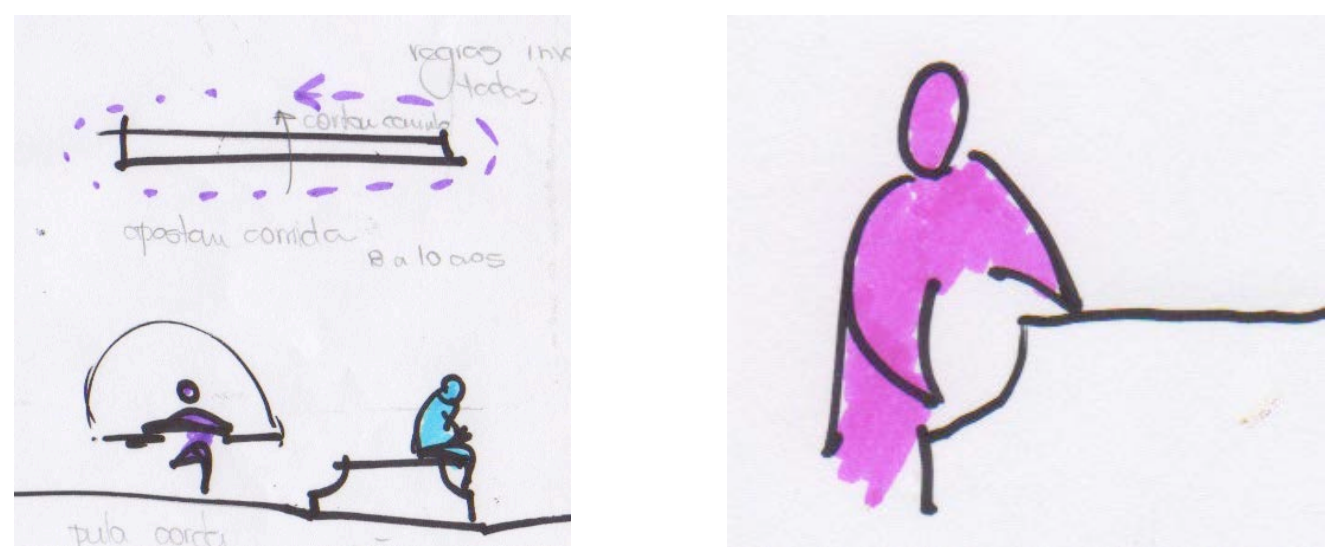

Figura 9 - Croqui representa a situação 3 gerar percursos: criança pulando corda contorna o canteiro central e aposta corrida com amiga.

Figura 10 - Croqui representa a situação 4 desafio da escalada e do equilíbrio: criança apoiando-se na mureta central para escalá-la.

Fonte: elaborado por Graziela Nivoloni (2015), com base na pesquisa realizada.

\subsection{Discussão}

É fundamental que se estabeleça uma abordagem centrada no usuário para que o processo projetual relativo ao brincar infantil se modifique parcial ou integralmente em alguns aspectos como: ter a participação e/ou coautoria das crianças, compreender sua linguagem e seu universo cultural; familiarizar-se com suas formas de expressão e, especialmente, como apropriam-se do espaço. Elvira de Almeida (1997) sugeria postura semelhante, pois defendia que os brinquedos e equipamentos deveriam dar suporte à atividade, sem restringi-la. Conclui-se, portanto, que observar e analisar como elas próprias criam e recriam seus espaços para brincar, como o delimitam e com que o fazem é crucial.

Além da observação não participante, outro método que poderia ter sido aplicado e possui certa eficácia, é a observação de medidas ocultas, unobtrusive measures (Gray, 2004, p.263). Poderia ser aplicado por meio da avaliação de crianças que levam bicicletas, skates, patins e afins e que, em razão do estímulo para explorar o espaço, deixam-nos de lado a fim de divertirem-se de outra maneira. Na verdade, analisar se isso ocorreu, a forma como se deu o evento e com que crianças teria acontecido, poderia trazer novas e surpreendentes informações. A questão de que, somente crianças que não possuem estes objetos, brincam livremente no Elevado, poderia ser repensada e revista.

Ademais, identificou-se a necessidade de, por meio de outro método de coleta de dados não visuais, obter expressões próprias dos usuários, verbais ou não, para apreender aspectos que não são percebidos ou caracterizados por meio do uso do espaço ou da maneira como comportam-se nele. Acredita-se que se tornaria mais completo o entendimento e a avaliação do evento se os usuários pudessem expressar-se sobre o que sentem e percebem, suas motivações e expectativas em relação ao uso do Elevado Costa e Silva para o brincar infantil.

Segundo Flick (2009, p.32), essa triangulação de diversos métodos qualitativos suprimiria as limitações de um método único, combinando-os e amenizando ou eliminando falhas e lacunas que um deles poderia vir a apresentar. 


\section{CONCLUSÃO}

"Como pode valer a pena tentar compreender algo tão ruim?" (Jacobs, 2001, p.21). Mesmo em situação tão adversa, como a apresentada no local de estudo, mesmo que o foco da coleta de dados seja o ser humano em formação e desenvolvimento, a criança, deve-se buscar compreendê-la, analisá-la da maneira mais aprofundada possível, reconhecendo sua individualidade, idiossincrasias, habilidades e interesses, de forma empática (sem pré-julgamentos ou preconceitos), e com ela, aprender. Esta postura impediria que o designer ou arquiteto definisse, segundo suas convicções e percepções, o que as crianças devem fazer, de que modo devem brincar, criar metas e desafios à sua perspectiva e até em que sequência se desenvolverá tal atividade.

Defende-se que elas devem sentir-se livres, estimuladas e seguras para fazê-lo como lhe aprouverem. Cabendo, aos profissionais que pensam e projetam para o brincar, dar suporte de modo que as crianças consigam fazê-lo de forma efetiva e que aproveitem a oportunidade para se relacionarem entre si, desenvolverem aptidões, vencerem desafios e criarem novas formas de brincar e explorar o mundo.

\section{REFERÊNCIAS}

ALMEIDA, Elvira. Arte Lúdica. São Paulo: EDUSP, 1.997, p.49.

.A criança e a invenção de seu espaço. A expressão lúdica como elo entre o designer e o usuário. Dissertação ( Mestrado em Arquitetura ) 1.985 - sob orientação da Profa. Dra. Lucrécia D’Aléssio Ferrara. - Faculdade de Arquitetura e Urbanismo, Universidade de São Paulo, São Paulo.

A Escultura Lúdica e o Cenário de Brincar: Trajetória poética de uma experiência intervindo no urbano com as sucatas que a cidade abandona. 1993. Tese ( Doutorado em Arquitetura e Urbanismo ) - Faculdade de Arquitetura e Urbanismo, Universidade de São Paulo, São Paulo.

BANKS, Marcus. Los datos visuales en investigación cualitativa. Trad. C. Blanco Castellano y T. Del Amo Martin. Madri: Ediciones Morata, 2010, p. 12-29.

DESIGN OTHER 90. About design with the other 90\%: Cities. Disponível em <http://www.designother90.org>. Acesso em: 10 set. 2014.

EYCK, Aldo Van. The child, the city and the artist. Holanda, 1962.

FLICK, Uwe. Introdução à pesquisa qualitativa. Porto Alegre, 2009, p. 32.

GRAY, David. Doing research in the real world. Londres, 2004, p. 238-266.

Hayakawa, S.I.; Hayakawa, A.R. Language in thought and action. New York: Harvard, 1990.

JACOBS, Jane. Morte e vida das grandes cidades. São Paulo, 2001, p. 12-13.

MARTINHO, Joana Isabel Pereira. $O$ espaço para a criança na cidade:

Um estudo crítico a partir da experiência de Aldo Van Eyck. 2014. Dissertação

(Mestrado Integrado em Arquitetura) Universidade do Porto, Porto, p. 4. 
NASCIMENTO, Andrea Zemp Santana. A criança e o arquiteto: quem aprende com quem? 2009. Dissertação (Mestrado em Arquitetura e Urbanismo) - Faculdade de Arquitetura e Urbanismo, Universidade de São Paulo, São Paulo, p.27-56.

NASCIMENTO, Nayana Brettas. A cidade (re)criada pelo imaginário e cultura lúdica das crianças: Um estudo em sociologia da infância. 2009. Dissertação (Mestrado em Estudos da Criança - Sociologia da Criança) - Universidade do Minho, Braga.

SINGER, Dorothy; GOLINKOFF, Roberta M.; HIRSH-PASEK, Kathy. Play = Learning: How play motivates and enhances children's cognitive and social-emotional growth. Nova lorque: Oxford University Press, 2006.

VAINER, Andre; FERRAZ, Marcelo (org.). Cidadela da Liberdade: Lina bo Bardi e o SESC Pompéia. São Paulo: Edições SESC, 2013.

WINNICOT, Donald W. O brincar $\&$ a realidade. Trad. José Octavio de Aguiar Abreu e Vanede Nobre. Rio de Janeiro: Imago, 1.975, p. 89-185. 